\title{
PREVALENCE OF ACUTE ABDOMEN ADMISSION IN SURGERY WARD AT TERTIARY CARE CENTER OF NEPAL
}

\author{
Rajesh Poudel, ${ }^{1}$ Anand Kumar, ${ }^{1}$ Kailash Chandra, ${ }^{1}$ Santosh Shah, ${ }^{1}$ Naveen Mahasheth, ${ }^{1}$ Santosh Mishra, ${ }^{1}$ Kumar Paudel ${ }^{1}$
}

\section{ABSTRACT}

\section{INTRODUCTION}

Abdominal pain is one of the most common reasons for an emergency department visit, accounting to about $8 \%$ of all emergency visits in United States. There are very few data available regarding the emergency admission of acute abdomen in Nepal.

The aim of this study is to determine the prevalence of acute abdomen admission and their frequency according to the age, sex and month of admission in hospital.

\section{MATERIAL AND METHODS}

This was a retrospective descriptive study carried out in Universal College of Medical Sciences, Bhairahawa, Nepal. Admission registers of surgery ward from July 2017 to June 2018 were reviewed. Data regarding the diagnosis, age, sex and month of admission of the patients were collected. Descriptive analyses were done regarding the frequency of disease, distribution of the diseases according to the age, sex and month of occurrences.

\section{RESULTS}

Total of 675 patients with acute abdomen were analyzed. Acute appendicitis was the most common cause for acute abdomen accounting for $52 \%$ of total admission. It was followed by intestinal obstruction (13\%) and acute cholecystitis (11\%). Median age of presentation of acute appendicitis was 23 years. Median age of presentation of acute cholecystitis was 42 years. Acute abdomen occured most frequently on April, May and December. Overall, spring season had highest number of admission (31.5\%) followed by winter $(25.6 \%)$.

\section{CONCLUSION}

Acute abdomen incidence varies according to age, most commonly found in young adults. Male has higher prevalence of acute abdomen when compared to female with exception of acute cholecystitis.

KEYWORDS: Acute abdomen, prevalence in Nepal, pain abdomen

1. Department of Surgery, Universal College of Medical Sciences, Bhairahawa, Nepal

DOI: https://doi.org/10.3126/jucms.v7i1.24678

\author{
For Correspondence \\ Dr. Rajesh Poudel \\ Department of Surgery \\ Universal College of Medical Sciences \\ Bhairahawa, Nepal. \\ Email: rajeshpoudel@yahoo.com
}




\section{INTRODUCTION}

Acute abdomen is a condition that demands urgent attention and treatment. It is characterized by pain arising from the abdominal area, of non-traumatic origin with a maximum duration of five days. ${ }^{1}$ The acute abdomen may be caused by an infection, inflammation, vascular occlusion or obstruction. Abdominal pain is one of the most common reasons for an emergency department visit, accounting to about $8 \%$ all emergency visits in United States. ${ }^{2}$ There are very few data available regarding the emergency admission of acute abdomen in Nepal. The aim of this study was to determine the prevalence of acute abdomen admission and their frequency according to the age, sex and month of admission in hospital.

\section{MATERIAL AND METHODS}

This was a retrospective descriptive study carried out in Universal College of Medical Sciences, Bhairahawa, Nepal. The institutional review committee, UCMS, Bhairahawa, approved this study. Admission registers of surgery ward from July 2017 to June 2018 were reviewed. All patients admitted in surgical ward with complains of acute pain abdomen were included in the study. Those who had traumatic injury of abdomen were excluded. Pain abdomen of urological and gynaecological origin were also excluded. Data regarding the diagnosis, age, sex and month of admission of the patients were collected. Data was entered in Microsoft Excel. Descriptive analyses were done regarding the frequency of disease, distribution of the diseases according to the age, sex and month of occurrences.

\section{RESULTS}

Total of 675 patients with acute abdomen were analyzed. Acute appendicitis was the most common cause for acute abdomen accounting for $52 \%$ of total admission. It was followed by intestinal obstruction (13\%) and acute cholecystitis (11\%). Other common causes of acute pain abdomen needing surgical admission were hollow viscous perforation, acute biliary pancreatitis, liver abscess and diverticulitis. About five percent of the patients' diagnosis could not be established (Table 1).Median age of presentation of acute appendicitis was 23 years with the range 5-89 years. Male to female ratio was 1.27:1. Median age of presentation of

Table 1. Spectrum of disease in patients with acute abdomen

\begin{tabular}{lll}
\hline Diagnosis & Number & Percentage (\%) \\
\hline Acute Appendicitis & 352 & 52 \\
Intestinal obstruction & 86 & 13 \\
Acute Cholecystitis & 77 & 11 \\
Hollow viscus perforation & 65 & 10 \\
Acute Biliary Pancreatitis & 42 & 6 \\
Pain abdomen of unknown & 31 & 5 \\
origin & & \\
Liver Abscess & 15 & 2 \\
Meckel Diverticulitis & 7 & 1 \\
\hline Total & 675 & 100 \\
\hline
\end{tabular}

acute cholecystitis was 42 years with the age range from 21 to 75 years. Male to female ratio was 1:1.58. Median age of presentation for hollow viscus perforation was 45 years with the age range from 10-77 years. Male to female ratio was 3.64:1 (Table 2)

Table 2. Distribution of disease according to sex and their median age with age range

\begin{tabular}{|c|c|c|c|c|}
\hline Diagnosis & Male & Female & $\begin{array}{l}\text { Range } \\
\text { (years) }\end{array}$ & $\begin{array}{l}\text { Median } \\
\text { age (years) }\end{array}$ \\
\hline Acute Appendicits & 197 & 155 & $5-89$ & 23 \\
\hline Acute Cholecystitis & 28 & 44 & $21-75$ & 42 \\
\hline $\begin{array}{l}\text { Hollow viscus } \\
\text { perforation } \\
\text { Acute Biliary }\end{array}$ & 51 & 14 & $10-77$ & 45 \\
\hline Pancreatitis & 21 & 21 & $13-68$ & 38 \\
\hline $\begin{array}{l}\text { Pain abdomen of } \\
\text { unknown origin }\end{array}$ & 16 & 15 & $11-65$ & 24 \\
\hline Liver Abscess & 10 & 5 & $25-65$ & 43 \\
\hline Meckel Diverticulitis & 5 & 1 & $2-44$ & 23 \\
\hline
\end{tabular}

Acute abdomen occured most frequently on April, May and December. Overall, spring season had highest number of admission $(31.5 \%)$ followed by winter $(25.6 \%)$. Frequency was lowest on autumn season (17.6\%) (Figure 1).

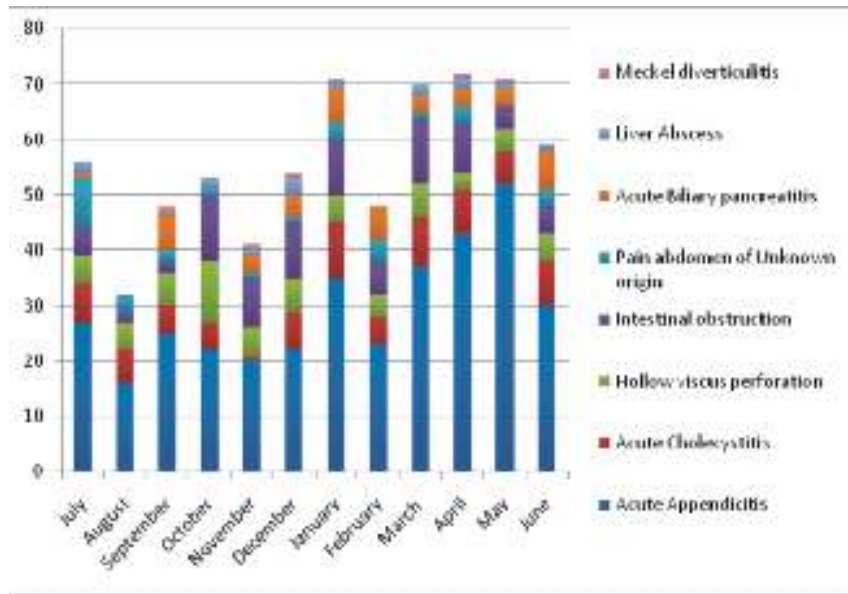

Figure 1. Distribution of diseases according to the month of admission

\section{DISCUSSION}

Acute appendicitis was most common finding of our study accounting for $52 \%$ of acute abdomen. Second common finding was intestinal obstruction followed by acute cholecystitis. Similar findings were found in a study done by Malviya A et al,where they found acute appendicitis to be most common cause followed by intestinal obstruction. However, they observed hollow viscus perforation more frequently than acute cholecystitis. ${ }^{3}$ In contrast, our findings suggest acute cholecystitis was more common than perforation. ${ }^{3}$ Similar findings were also found by Aijaz et al in regard to frequency of acute appendicitis and intestinal obstruction. Their study also showed that hollow viscus perforation being more 
common cause of acute abdomen than acute cholecystitis contrasting our study.

Acute abdomen frequently occurs in younger adult age group. ${ }^{4,5}$ Similar findings were noted in our study where median age of presentation was 23 years for appendicitis, 42 years for acute cholecystitis and 45 years for hollow viscus perforation.

Frequency of acute abdomen in male is higher than female in most of the acute abdomen cases except for acute cholecystitis.

The month of May had the highest incidence for acute appendicitis in the present study. Similar study has been done by Yu-Ching Tseng et al. where they found that peak incidence of appendicitis was in September that contrast our study. ${ }^{6}$ Spring season overall has the highest incidence of acute abdomen.

There are several limitations to this study. Because of its retrospective design, there were missing entries in the file during data collection. Diagnostic criteria for acute abdomen were not well mentioned. Causes of paediatric acute abdomen that were managed conservatively could not be analysed as most of the data were entered in paediatric ward registers and missing from surgical registers.

\section{CONCLUSION}

Acute abdomen incidence varies according to age, most commonly found in young adults. Male has higher prevalence of acute abdomen when compared to female with exception of acute cholecystitis.

\section{REFERENCES}

1. Gans SL, Pols MA, Stoker J, Boermeester MA, Expert Steering Group. Guideline for the diagnostic pathway in patients with acute abdominal pain. Digestive surgery. 2015;32(1):23-31.

2. National Center for Health Statistics (NCHS). National Hospital Ambulatory Medical Care Survey: 2010 Emergency Department Summary Table. Centers for Disease Control and Prevention, http://www.cdc.gov/ nchs/data/ahcd/nhamcs_emergency/ 2010_ed_web_tables.pdf (2010, accessed 15 May 2015).

3. Malviya A, Hussain A, Bulchandani HP, Bhardwaj G, Kataria S. A comprehensive study on acute non-traumatic abdominal emergencies. International Surgery Journal. 2017 Jun 22;4(7) :2297-302.

4. Memon AA, Bhutto AA, Shaikh GS, Jokhio A, Soomro QA. Spectrum of diseases in patients with non-traumatic acute abdomen. J Liaquat Uni Med Health Sci. 2008 Sep;7(3):180-3.

5. Poudel R, Shah S, Chandra K, Pradhan S, Joshi P. Spectrum of Perforation Peritonitis In Western Nepal. Journal of Universal College of Medical Sciences. 2018;6(1):11-3.
6. Tseng YC, Lee MS, Chang YJ, Wu HP. Acute abdomen in pediatric patients admitted to the pediatric emergency department. Pediatrics \& Neonatology. 2008 Aug 1;49(4):12634. 